\section{Blair to seek consensus on safe greenhouse-gas levels}

\section{Jim Giles, London}

Tony Blair, the British prime minister, plans to adopt a controversial new approach to international negotiations on climate change, according to UK scientists.

The approach, which his government is expected to announce later this month, would ask world leaders to seek agreement on an acceptable target level for the concentration of greenhouse gases in the atmosphere. But climate-change experts in Britain have expressed concern that such a strategy could dilute existing attempts to cut emissions of greenhouse gases, through the implementation of the Kyoto Protocol (see page 613).

With Blair hosting a meeting of the Group of Eight industrialized nations (G8) at Gleneagles in Scotland next July, and Britain holding the rotating presidency of the European Union for six months after that, the prime minister wants to provide some global impetus towards action on climate change.

Blair's initiative would get government leaders to work out how they could declare a level at which atmospheric greenhouse-gas concentrations would become "dangerous", say researchers who have discussed the idea with UK government officials. Supporters of the idea believe that discussion of such a long-term limit could help break the deadlock between countries that have ratified the Kyoto Protocol and others, led by the United States, that have rejected it.

UK scientists who have been consulted on the plan welcome Blair's focus on climate change, but warn that it will be hard to reach political or scientific agreement over what constitutes a dangerous level of greenhouse gases. They say that they have expressed their concerns during consultations for a government-run conference on greenhouse-gas stabilization that will take place next February at the Hadley Centre for Climate Prediction and Research in Exeter.

"Any attempt to launch negotiations on a target would be extremely dangerous and misguided," says Michael Grubb, a specialist in climate-change policy at Imperial College London. He says he received a "stony reception" from environment ministry officials when he made this point to them last month at a meeting at the Tyndall Centre for Climate Change Research in Norwich.

Grubb and others say that consideration of such a greenhouse-gas target will lead different countries in divergent directions, with each one looking at local problems, such as the effect of climate change on staple crops or on the frequency of summer heat-

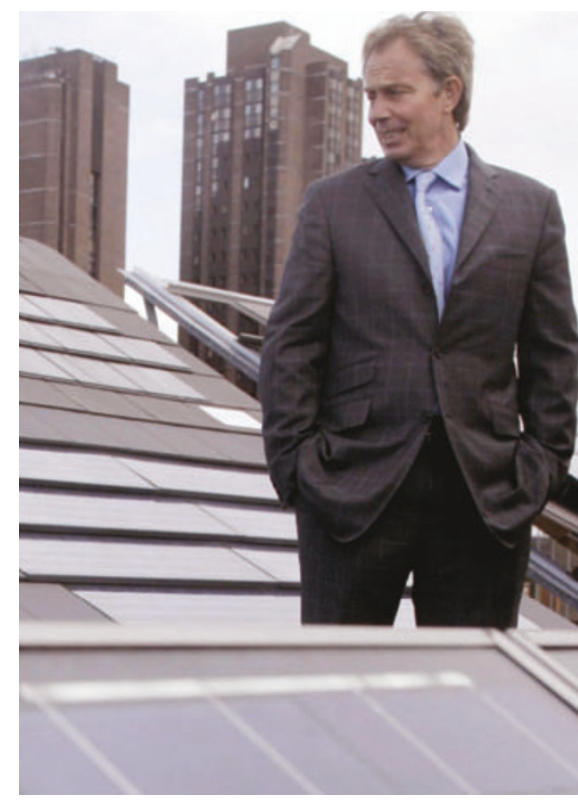

Tony Blair wants action on global warming.

waves. David Griggs, director of the Hadley Centre - who has also been consulted by the environment ministry - says he fears that nations will find little common ground for identifying such a target.

And Mike Hulme, director of the Tyndall Centre, who is due to meet with ministry officials next week, says that the idea of a global target for greenhouse gases is too distant from people's immediate concerns about the impact of climate change. "It's too remote" he says. "It's not good at changing people's behaviour."

David Warrilow, a ministry official who is involved in the consultation, says that the British government wants other nations to "start to think about progress" towards setting a stabilization level, rather than establishing a firm target. Such debate could feed into future Kyoto Protocol negotiations, he adds.

But some climate-change analysts say the issue will simply divert attention from the pressing need to control emissions of greenhouse gases. "We could invest an enormous amount of time in a fruitless exercise," says Elliot Diringer, director of international strategy at the Pew Center on Global Climate Change in Washington, "rather than focussing on what can be done now."

Diringer agrees that the scope of the Kyoto Protocol should be broadened during its second phase, but he suggests that any new targets should focus on variables over which nations have direct control, such as levels of energy efficiency or the capture and storage of carbon dioxide.

\section{Britain warms to European space exploration plan}

Jim Giles, London

Italy and Britain look set to take a leading role in a major European Space Agency (ESA) initiative to explore the Solar System, which could culminate in a manned mission to Mars.

The involvement of Britain, which pledged $€ 7$ million (US\$8.6 million) of initial funding on 1 October, marks a significant re-engagement in ESA projects. Britain did not participate in the agency's work on the International Space Station (ISS), but has recently been taking a more positive approach to ESA. In the past, it has taken a dim view of some of the space agency's more ambitious projects, including its astronaut programme.

Britain will now play a prominent role in the Aurora exploration programme, although the contribution from Italy $€ 14$ million, to be confirmed by midOctober - will give that country the largest single influence on the project. Germany has yet to commit to the programme, and France says it will only supplement the limited funding it has already provided if uncertainties surrounding the future of the ISS can be resolved (see Nature 423, 103; 2003).

Details of the programme are due to be agreed by early 2006, but all parties admit that much has yet to be decided. Britain would like Aurora to focus on robotic missions, whereas Italy and France would like it to have a substantial manned component.

Whatever form the plans finally take, the programme will be costly. Britain's Particle Physics and Astronomy Research Council (PPARC), the funding body that pays the UK subscription to Aurora, says ESA may ask it for around $€ 35$ million a year. That is probably "wishful thinking" on the space agency's part, says PPARC chief executive Ian Halliday, unless his council receives extra funding from the UK government.

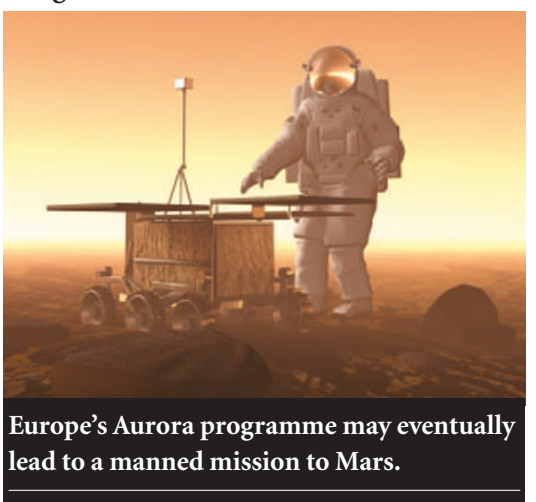

